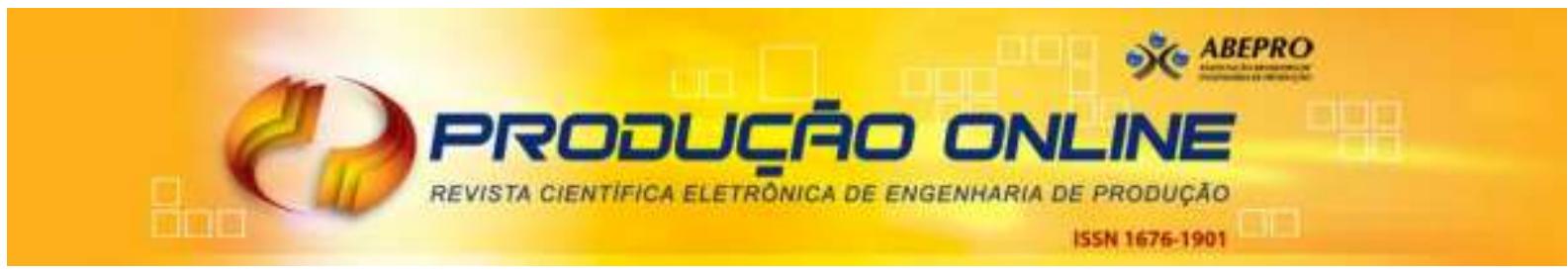

\title{
AVALIAÇÃO DE PRESENÇA DE RECURSOS ALTERNATIVOS EM PLANO DE PROCESSOS PARA MELHORAR O DESEMPENHO DE SISTEMAS MANUFATURA
}

\section{EVALUATING THE PRESENCE OF ALTERNATIVE RESOURCES IN PROCESS PLANNING TO IMPROVE THE PERFORMANCE OF MANUFACTURING SYSTEMS}

\author{
Mario Henrique de Mello* E-mail: mariohmello@gmail.com \\ João Carlos E. Ferreira*E-mail: jcarlos@emc.ufsc.br \\ * Universidade Federal de Santa Catarina (UFSC), Florianópolis, SC
}

Resumo: Usualmente os planos de processos são gerados sem considerar a utilização de máquinas alternativas, isto é, no planejamento de processo convencional uma única máquina é selecionada para a execução de uma determinada operação. Com isso, as máquinas preferidas pelos processistas são selecionadas para executar a maioria das tarefas, ocasionando a formação de gargalos na produção. Nesse contexto, a inclusão de máquinas alternativas em planos de processo pode ser usada como uma estratégia para resolver o problema de formação de gargalos, pois a eventual indisponibilidade de uma máquina permite que outra máquina pré-planejada seja selecionada e utilizada imediatamente. Para avaliar essa proposta, foi desenvolvido um modelo para simulação de um sistema de manufatura sujeito aos dois tipos de planos de processo, isto é, com ou sem máquinas alternativas. Verificou-se que a inclusão de máquinas alternativas em planos de processo resulta na melhoria no desempenho do sistema de manufatura em relação à produtividade, ao estoque em processo e à utilização de máquinas, ainda que a máquina alternativa selecionada tenha uma menor eficiência.

Palavras-chave: Planos de processo com alternativas. Gestão da produção. Simulação. Gargalos na produção.

\begin{abstract}
Usually the process plans are generated without considering the use of alternative machines, i.e., in conventional process planning a single machine is selected for the execution of a particular operation. Consequently, the machines that are preferred by process planners are selected to perform most tasks, leading to the formation of bottlenecks in production. In this context, the inclusion of alternative machines in process plans can be used as a strategy to solve the bottleneck formation problem, since the possible unavailability of a machine allows another preplanned machine to be selected and used immediately. In order to evaluate this proposal, a model was developed to simulate a manufacturing system subject to both types of process plans, i.e., with or without alternative machines. It was found that the inclusion of alternative machines for plans process results in improved performance of the manufacturing system with regard to productivity, work-in-process, and machine utilization, even if the selected alternate machine has lower efficiency.
\end{abstract}

Keywords: Process Plans with Alternatives. Production Management. Simulation. Production Bottlenecks. 


\section{INTRODUÇÃO}

O planejamento do processo tem como propósito a definição das informações tecnológicas (p.ex. seqüência de operações, parâmetros de corte) e recursos produtivos (p.ex. máquinas, ferramentas, dispositivos de fixação) necessários para fabricar uma peça. No caso de um plano de processo convencional, isto é, sem a presença de recursos alternativos, normalmente apenas um recurso produtivo é selecionado na fabricação de uma peça, enquanto no caso de um plano de processo com alternativas, pode-se selecionar mais de um recurso. $O$ uso de alternativas em planos de processo aparece na literatura como uma opção para melhorar o desempenho de sistemas de manufatura (i.e. SORMAZ et al., 2010; CHUNG e SUH, 2008; SORMAZ e KHOSHNEVIS, 2003; WEINTRAUB et al., 1999; MAHMOODI et al., 1999; BECKENDORFF et al., 1991, entre outros), pois permite a imediata tomada de decisões sobre a execução de uma ordem de produção mesmo sob condições dinâmicas inesperadas, como a quebra de máquina, falta de ferramentas e sobrecarga dos recursos. Isso pode ser realizado porque recursos alternativos (p.ex. máquinas, ferramentas, elementos de fixacao) já foram previstos com antecedência na elaboração do plano de processo. Em geral, o uso de alternativas é mais comum em leiautes funcionais (KIS, 2003), porém seu uso também pode ser extendido para leiautes celulares (SOFIANOPOULOU, 1999). No caso de leiautes celulares, máquinas alternativas existentes em outras celulas podem ser utilizadas como rota de contingencia no caso de interrupcoes ou sobrecarga na celula principal (AHKIOON et al., 2009).

Outro benefício na utilização de alternativas consiste na sua utilização como estratégia para evitar a formação de gargalos na produção (JOSEPH e SRIDHARAN, 2012; CHAN, 2003) como se propõe neste trabalho. Neste caso, as alternativas são utilizadas visando uma distribuição mais eqüitativa da carga de trabalho entre os recursos produtivos. Geralmente a seleção de recursos alternativos é feita somente na impossibilidade de se executar um plano de processo, mas neste trabalho um recurso alternativo pode ser selecionado para executar uma operação mesmo quando o recurso selecionado originalmente possa executar a operação. Nessa circunstância, o que leva à seleção de um recurso alternativo, que neste caso 
é uma máquina, é o estoque em processo (Work In Process - WIP) alocado na máquina selecionada inicialmente. Por exemplo, se um lote foi selecionado para ser executado em uma determinada máquina, mas por algum motivo o estoque em processo nesta máquina for maior que o de uma máquina alternativa, a máquina alternativa será selecionada para fabricar o lote. Desse modo, pode-se reduzir o estoque em processo nas máquinas gargalo, e aumentar a produtividade ainda que o recurso alternativo tenha uma produtividade menor, como será mostrado neste trabalho. Para averiguar se essa estratégia leva a bons resultados, foi realizado um experimento combinando simulação baseada em eventos discretos (OLIVEIRA et al., 2009) e projeto de experimentos, no qual considerou-se não só a influência do plano de processos (sem ou com alternativas) como também fatores associados à demanda (PEREIRA et al., 2008) e à complexidade das peças. O modelo de simulação que foi desenvolvido permitiu reproduzir as incertezas existentes no sistema real, tais como: a possibilidade de falha nas máquinas e ferramentas, distribuição de probabilidade tanto para o tempo de chegada de uma ordem, bem como para o tempo de transporte. Ao final é apresentada a análise de variância (ANOVA) (MONTGOMERY, 1997) para possibilitar a confirmação das análises realizadas a partir dos gráficos de efeito e interação. O desempenho do sistema de manufatura foi avaliado em relação à produtividade, ao estoque em processo e à utilização das máquinas.

\section{REVISÃO DA LITERATURA}

\subsection{Alternativas em Planos de Processo para Evitar Gargalos}

As instruções do plano de processo ditam o custo, qualidade e taxa de produção, portanto, o planejamento de processos é de extrema importância para o sistema de produção (CHANG et al., 1998). Isso faz do planejamento de processos uma atividade chave em qualquer empresa de manufatura, embora nem sempre receba a merecida importância. Usualmente, a elaboração de planos de processo não considera recursos alternativos, embora na literatura a utilização de alternativas em planos de processo já está disponível há algum tempo (PRABHU et al., 1990). 
Assim, ao selecionar determinada máquina para executar uma operação sobre a peça, o profissional responsável pela elaboração do plano de processo, chamado de 'processista', seleciona apenas um tipo de máquina, mesmo que em alguns casos possa existir mais de uma. Por exemplo, para se realizar um furo sobre uma peça, pode-se usar tanto uma furadeira como uma fresadora. Embora, a princípio, por razões econômicas (p.ex. custo da máquina, treinamento de operadores, etc.) o uso da furadeira seja mais vantajoso, em uma situação cuja furadeira não esteja disponível por alguma razão, a fresadora poderia ser utilizada se tivesse sido selecionada e estivesse disponível para realizar a operação. Mas essa situação só é levada em consideração em um plano de processos com alternativas.

Em um plano de processos com alternativas, recursos alternativos são previamente selecionados para realizar uma operação. Assim podem ser consideradas alternativas de máquina, ferramenta, seqüência de processamento, dispositivos de fixação, etc. Com isso, todo o trabalho efetuado na seleção de recursos alternativos proporciona ganhos em flexibilidade e produtividade (BAYKASOGLU e ÖZBAKIR, 2008; USHER, 2003).

Mesmo nos sistemas de manufatura que empregam um elevado nível de automação em seus processos, e em razão disso exista uma reduzida probabilidade de falhas, é impossível prever todas as possíveis interrupções que podem surgir no chão de fábrica (SAYGYN et al., 2001). Assim, a quebra de uma máquina, a falha de uma ferramenta, ou a impossibilidade de se utilizar um recurso programado para realizar uma determinada operação leva à interrupção da produção. A ocorrência de uma interrupção pode fazer com que um recurso se torne gargalo temporariamente até que a situação volte a se normalizar. Essa situação pode se tornar ainda mais crítica se no momento de uma interrupção as intervenções são efetuadas sob pressão ou por pessoal não qualificado para tal atividade, o que aumenta a possibilidade de erros, ocasionando maiores atrasos nos prazos de entrega ou prejuízos decorrentes dos improvisos adotados visando restabelecer o processo (FERREIRA e WYSK, 2001a, 2001b). Além disso, muitos dos improvisos adotados podem comprometer a qualidade dos produtos e, conseqüentemente, gerar aborrecimentos dos clientes. Nesse contexto, a adoção de alternativas em planos de processos pode proporcionar maior rapidez e eficiência na solução de interrupções 
na produção, pois uma ferramenta ou máquina alternativa já foi previamente incluída no plano de processos (i.e. SORMAZ e KHOSHNEVIS, 2003; SAYGYN et al., 2001; CHANG e CHEN, 2002).

\subsection{Trabalhos Relacionados}

Deja e Siemiatkowski (2012) propõem um sistema em que o modelo do produto, a capabilidade do sistema de manufatura e as restrições do processo são usadas como dados de entrada para agrupar pecas semelhantes de forma a otimizar a produção. Eficientes estratégias de processo são selecionadas com base na disponibilidade de elementos de fixação e conjunto de ferramentas. O sistema proposto por Deja e Siemiatkowski (2012) foi testado em um estudo de aplicação real, demonstrando a aplicabilidade do uso de alternativas para lidar com incertezas no chão de fabrica. De fato, existe uma crescente necessidade dos sistemas de manufatura de se adaptar às condições de mercado (externas) e do chão de fábrica (internas) (BARRETO et al., 2005). Em vários estudos, o uso de máquinas alternativas (também chamadas de rotas alternativas) tem se mostrado eficaz para aumentar a robustez do sistema de manufatura (AHKIOON et al., 2009).

Outros trabalhos recentes sobre a viabilidade do uso de alternativas em planos de processo envolvem a integração do planejamento do processo com a programação da produção (por exemplo, NONAKA et al. 2012; LI et al. 2010; WANG e SHEN, 2007; KIS 2003; MAHESH e SRINIVASAN 2002). De fato, existe um crescente interesse pelo uso de alternativas nesse contexto ( $L I$ et al. 2010). A programação da produção normalmente é uma etapa posterior ao planejamento do processo, porém essas duas funções são complementares. Portanto, uma maior colaboração entre essas duas funções pode proporcionar melhorias significativas no desempenho de sistemas de manufatura (WANG e SHEN, 2007). Além disso, a possibilidade de incorporar alternativas em planos de processo nos sistemas de monitoramento e controle em chão de fábrica (Manufacturing Execution System MES) resulta em melhorias nos processos de decisão (NONAKA et al. 2012). Todavia, o aumento no número de alternativas aumenta drasticamente a quantidade de programas de produção a serem analisados, e essa situação cria um problema 
complexo durante o planejamento e controle da produção (PCP). Vários métodos têm sido propostos para resolver esse problema e viabilizar o uso de alternativas. Li et al. (2010) e Phanden et al. (2011) oferecem uma detalhada revisão dos vários métodos usados para integrar o planejamento de processos com a programação da produção. De acordo com Li et al. (2010), a questão chave é como eliminar as desvantagens dos diversos métodos de integração disponíveis atualmente, neste sentido as técnicas de simulação podem ser usadas para propor soluções mais efetivas.

Outros trabalhos sobre a utilização de alternativas em sistemas de manufatura envolvem muitas vezes sistemas flexíveis de manufatura (FMS). Uma possível razão para isso é a flexibilidade obtida nesses sistemas ser tradicionalmente aquém do esperado. Isso porque, segundo Ferreira e Wysk (2001a), o software de controle não é flexível o suficiente para possibilitar a alteração do plano de processos em tempo real, por isso alguns problemas poderão afetar a produção. Nesse contexto Caprihan e Wadhwa (1997) apresentam uma metodologia baseada em Taguchi e simulação para analisar a influência de rotas alternativas no desempenho de um FMS. Caprihan e Wadhwa (1997) mostraram que o uso de alternativas aponta para um aumento em flexibilidade das rotas, entretanto nem sempre essa flexibilidade é benéfica quando disponibilizadas com o custo de uma penalidade associada ao tempo de operação. Assim, o aumento do número de rotas flexíveis de uma para duas melhora o desempenho razoavelmente, mesmo ao custo de uma penalidade, mas continuando a aumentar a quantidade de rotas o aumento do desempenho não é garantido em termos da redução do tempo de entrega. Outras pesquisas, como de Usher (2003), também apontam para a mesma direção. Portanto, conclui-se que um pequeno número de boas alternativas é melhor que uma grande variedade de alternativas de baixo desempenho, além do fato de que um menor número de alternativas reduz a complexidade da programação. Outras pesquisas (MAHMOODI et al. 1999) avaliam os efeitos das regras de programação e rotas flexíveis no desempenho do FMS, e concluem que a presença de rotas flexíveis alivia os efeitos da sobrecarga e quebras no sistema de manufatura. 


\section{METODOLOGIA}

\subsection{Features Consideradas}

Uma feature corresponde a uma forma geométrica à qual estão associadas informações úteis para sua fabricação, tais como: dimensões, ferramentas, máquinas (SHAH e MÄNTŸLA, 1995). Neste trabalho foram disponibilizadas quatro tipos de features para a construção de peças prismáticas para o modelo de simulação, as quais são: furo, rebaixo, canal e cavidade. Para cada tipo de feature foram selecionadas cinco dimensões diferentes, como mostra a Tabela 1.

\subsection{Planejamento do Experimento}

Os fatores identificados estão relacionados ao tipo de plano de processo, à complexidade da peça (features por peça e features duplicadas), programação da produção (tempo de chegada, quantidade do lote e lotes simulados) e à quebra de máquina. As variáveis de resposta são a produtividade (peças/hora), o estoque médio em processamento (peças) e a utilização dos recursos (\%).

Como todas as possíveis combinações dos fatores foram consideradas, o experimento caracteriza-se como um projeto fatorial completo, para o qual algumas combinações são mostradas na Tabela 2, onde o sinal "+" e "-" estão associados aos níveis alto e baixo para cada fator, respectivamente.

Para reduzir os erros inerentes à variabilidade do sistema e obter o erro experimental, foram realizadas três simulações para um mesmo nível de cada fator, ou seja, cada experimento foi replicado três vezes (Montgomery, 1997). Como foram considerados sete fatores, cada um com dois níveis, isso resulta num total de $2^{7}=$ 128 experimentos. Como para cada fator são consideradas três replicações, a quantidade total de experimentos realizados foi de $3 \times 128=384$ experimentos. 
Tabela 1 - Dimensões da features utilizadas na formação das peças

\begin{tabular}{|c|c|c|c|c|c|}
\hline \multicolumn{6}{|c|}{ Furo } \\
\hline & Feature $n^{0}$ & Diâmetro (D) & \multicolumn{3}{|c|}{ Profundidade (P) } \\
\hline & 1 & 12 & \multicolumn{3}{|c|}{32} \\
\hline & 2 & 13 & \\
\hline & 3 & 18 & & & \\
\hline & 4 & 20 & \multicolumn{3}{|c|}{$\begin{array}{l}44 \\
55\end{array}$} \\
\hline & 5 & 22 & \multicolumn{3}{|c|}{60} \\
\hline \multicolumn{6}{|c|}{ Rebaixo } \\
\hline & Feature $\mathbf{n}^{0}$ & Comprimento (C) & \multicolumn{2}{|c|}{ Largura (L) } & Altura (A) \\
\hline & 6 & 80 & \multirow{2}{*}{\multicolumn{2}{|c|}{$\begin{array}{l}16 \\
18\end{array}$}} & 15 \\
\hline & 7 & 85 & & & 18 \\
\hline & 8 & 90 & \multicolumn{2}{|c|}{20} & 18 \\
\hline & 9 & 95 & \multicolumn{2}{|c|}{23} & 20 \\
\hline & 10 & 100 & \multicolumn{2}{|c|}{28} & 25 \\
\hline \multicolumn{6}{|c|}{ Canal } \\
\hline & Feature $n^{0}$ & Comprimento (C) & \multicolumn{2}{|c|}{ Largura (L) } & Altura (A) \\
\hline & 11 & 80 & \multicolumn{2}{|c|}{14} & 10 \\
\hline & 12 & 85 & \multicolumn{2}{|c|}{15} & 12 \\
\hline & 13 & 85 & \multicolumn{2}{|c|}{16} & 13 \\
\hline & 14 & 90 & \multicolumn{2}{|c|}{18} & 15 \\
\hline & 15 & 95 & \multicolumn{2}{|c|}{20} & 18 \\
\hline \multicolumn{6}{|c|}{ Cavidade } \\
\hline & Feature $\mathrm{n}^{\mathrm{o}}$ & Comprimento (C) & Largura (L) & Altura (A) & Raio (R) \\
\hline & 16 & 50 & 20 & 8 & 4 \\
\hline & 17 & 55 & 22 & 10 & 5 \\
\hline & 18 & 60 & 25 & 12 & 6 \\
\hline & 19 & 60 & 30 & 12 & 7 \\
\hline & 20 & 70 & 32 & 14 & 8 \\
\hline
\end{tabular}

\subsubsection{Fatores de Controle}

Os fatores selecionados são apresentados na Tabela 3 e descritos nas seções seguintes.

\section{Features por Peça}

No nível baixo, considera-se que uma peça possua de uma a três features, já no nível alto cada peça possui de sete a dez features. A Figura 1 exemplifica os diferentes níveis para esse fator, onde são mostradas duas possíveis peças geradas utilizando os níveis baixo (Figura 1a) e alto (Figura 1b), respectivamente, mantendose o fator features duplicadas no nível baixo. 
Tabela 2 - Exemplo da combinação de níveis dos fatores de controle utilizados no experimento

\begin{tabular}{ccccccc}
\hline $\begin{array}{c}\text { Tempo de } \\
\text { Chegada }\end{array}$ & $\begin{array}{c}\text { Quebra de } \\
\text { máquina }\end{array}$ & $\begin{array}{c}\text { Lotes } \\
\text { Simulados }\end{array}$ & $\begin{array}{c}\text { Quantidade } \\
\text { do lote }\end{array}$ & $\begin{array}{c}\text { Features } \\
\text { Duplicadas }\end{array}$ & $\begin{array}{c}\text { Features } \\
\text { por peça }\end{array}$ & $\begin{array}{c}\text { Tipo de } \\
\text { Plano }\end{array}$ \\
\hline- & - & - & - & - & - & - \\
- & - & - & - & - & - & + \\
- & - & - & - & - & + & - \\
- & - & - & - & - & + & + \\
- & - & - & - & + & - & - \\
- & - & - & - & + & - & + \\
- & - & - & - & + & + & - \\
- & - & - & - & + & + & + \\
- & - & - & + & - & - & - \\
- & - & - & + & - & - & + \\
- & - & - & + & - & + & - \\
- & - & - & + & - & + & + \\
- & - & - & + & + & - & - \\
- & - & - & + & + & - & + \\
- & - & - & + & + & + & - \\
- & - & - & + & + & + & + \\
\hline
\end{tabular}

Tabela 3 - Fatores de controle utilizados no experimento

\begin{tabular}{clcl}
\hline Fator & \multicolumn{1}{c}{ Descrição } & Nível & \multicolumn{1}{c}{ Valor } \\
\hline \multirow{2}{*}{ Features por peca } & Quantidade de features diferentes & - & 1 a 3 features por peça \\
& numa mesma peça. & + & 7 a 10 features por peça \\
Features duplicadas & Quantidade de duplicações de uma & - & 1 a 3 features \\
& mesma feature em cada peça. & + & 7 a 10 features \\
Quantidade do lote & Quantidade de peças contidas em & - & 10 a 50 peças \\
& cada lote. & + & 200 a 500 peças \\
Quebra de máquina & Estimativa do tempo médio entre & - & $500 \mathrm{~h}$ tempo médio entre falhas \\
& falhas. & + & $100 \mathrm{~h}$ tempo médio entre falhas \\
\multirow{2}{*}{ Tipo de plano } & Plano de processos considerado pode & - & Plano sem alternativas \\
& ou não apresentar alternativas. & + & Plano com alternativas \\
Tempo de chegada & Tempo para a chegada do próximo & - & 20 a 30\% do tempo usinagem \\
& lote em relação ao anterior. & + & 50 a $60 \%$ do tempo usinagem \\
Lotes simulados & Quantidade total de lotes simulados & - & 50 lotes \\
& em cada replicação. & + & 200 lotes \\
\hline
\end{tabular}

Figura 1 - Peças formadas em diferentes níveis do fator features por peça - (a) nível baixo; (b) nível alto

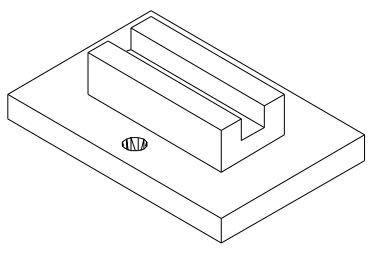

(a) Três features

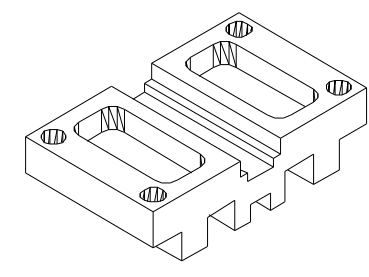

(b) Sete features 


\section{Features Duplicadas}

O nível baixo corresponde a uma variação de uma a três features iguais, enquanto no nível alto pode-se ter de sete a dez features iguais. Tanto este fator como o anterior estão diretamente relacionados à complexidade da peça a ser formada, portanto quanto mais alto o nível desses fatores maior será a complexidade da peça. A Figura 2 apresenta duas possíveis peças geradas considerando os níveis baixo (Figura 2a) e alto (Figura 2b), respectivamente.

Figura 2 - Peças formadas em diferentes níveis do fator features duplicadas - (a) nível baixo; (b) nível alto

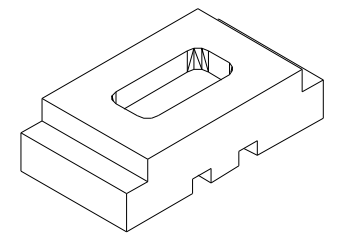

(a) 2 rebaixos, 2 canais e 1 cavidade

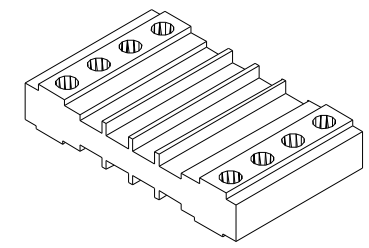

(b) 8 Furos, 8 rebaixos e 8 canais

\section{Tamanho do Lote}

Um lote pode conter uma quantidade variável de um mesmo tipo de peça em cada nível deste fator. No nível baixo a quantidade do lote varia entre dez e cinqüenta peças, enquanto que no nível alto os valores variam de duzentas a quinhentas peças.

\section{Tipo de Plano}

O nível baixo caracteriza um plano sem alternativas, isto é, apenas uma opção de máquina é selecionada para a execução de etapa do processo. Já o nível alto consiste no plano de processo com alternativas, e nesse caso foram consideradas duas opções de máquina para a execução de cada etapa do processo. Segundo Usher (2003), preferencialmente devem ser utilizadas apenas duas alternativas, pois uma quantidade maior de alternativas está associada à utilização de recursos de menor eficiência. Isto porque os recursos mais eficientes estão, na maior parte do tempo, sobrecarregados em razão de serem preferidos pelos processistas. 


\section{Tempo de Chegada}

Se o tempo de chegada de um lote em uma determinada máquina for menor que o tempo necessário para usinagem do lote anterior nesta mesma máquina, ocorrerão estoques em processo. Por outro lado, quando o tempo para a chegada de um lote numa máquina for maior que o tempo necessário para fabricar um lote anterior nesta mesma máquina, haverá ociosidade na máquina. Essas situações foram consideradas no experimento, com o tempo entre duas chegadas consecutivas de lotes aumentando de $10 \%$ até $100 \%$ do tempo de usinagem do lote anterior, conforme o nível desse fator.

\section{Lotes Simulados}

O nível baixo desse fator corresponde a uma maior variabilidade no tempo de chegada da ordem de fabricação, isto é, a uma maior incerteza quanto ao tempo para chegada de uma ordem de fabricação. No nível alto, esta incerteza será menor.

\subsubsection{Variáveis de Resposta}

\section{Produtividade}

O cálculo da produtividade $(P)$ é realizado considerando a quantidade total de peças produzidas $(Q)$ em um intervalo de tempo $(\Delta t)$, conforme mostra a Equação 1. A quantidade total de peças produzidas, dada pela Equação 2 é o somatório da quantidade de peças em cada lote produzido (q), considerando uma determinada quantidade de lotes ( $n)$.

$$
P=\frac{Q}{\Delta t}
$$

Onde:

$$
Q=\sum_{i=0}^{n} q
$$

\section{Estoque em Processo}

O estoque médio em processo (E) para cada máquina foi calculado com base na expressão apresentada por Law e Kelton (2000), a qual relaciona o somatório do tempo total de espera $\left(\Delta t_{e}\right)$ para todos os lotes simulados $(n)$, considerando a 
quantidade total de peças em cada lote $(q)$ no intervalo de tempo $(\Delta t)$, como se observa na Equação 3.

$$
E=\frac{\sum_{i=0}^{n}\left(\Delta t_{e} \cdot q\right)}{\Delta t}
$$

\section{Utilização das Máquinas}

A utilização de cada máquina é dada pela relação entre o intervalo de tempo de utilização $\left(\Delta \mathrm{t}_{\mathrm{u}}\right)$ do recurso e o intervalo de tempo $(\Delta \mathrm{t})$ que o mesmo estava disponível, como mostra a Equação 4.

$$
U=\frac{\Delta t_{u}}{\Delta t}
$$

\subsection{Modelo de Simulação}

A tarefa de simulação foi realizada em duas etapas, como ilustra a Figura 3. Na etapa de geração das ordens são realizadas as seguintes atividades: geração das features, definição da quantidade de features duplicadas, definição da quantidade do lote, geração da seqüência de usinagem e cálculo dos tempos de usinagem. Essas informações foram armazenadas em uma planilha de dados para em seguida, na próxima etapa, serem utilizadas no modelo de simulação do sistema de manufatura. Após execução da simulação, os resultados obtidos para as variáveis de resposta são armazenados em uma planilha de resultados da simulação.

Figura 3 - Estrutura do modelo de simulação

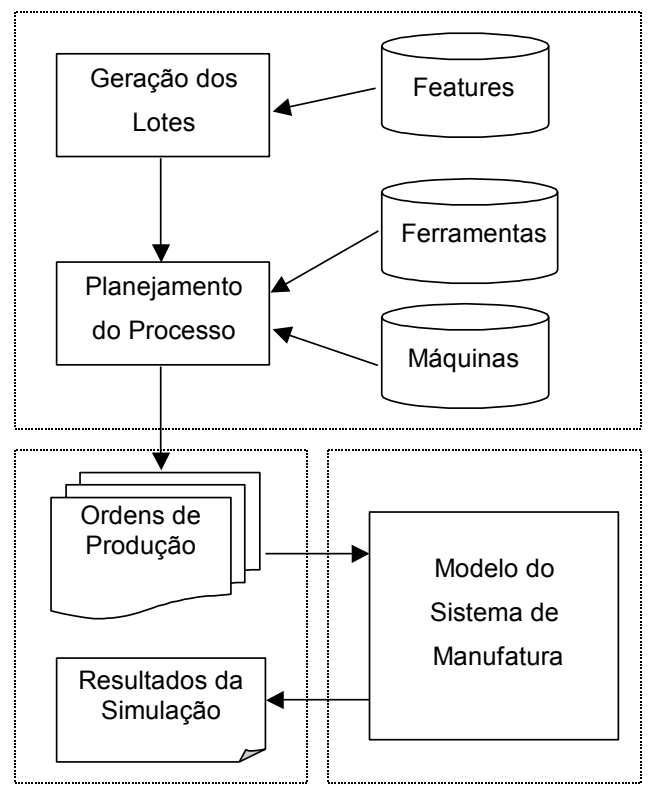




\subsubsection{Etapas para a geração da ordem de produção}

A geração da ordem de produção foi feita utilizando-se o software Microsoft Excel $^{\mathrm{TM}}$, com o suporte de macros em Visual Basic ${ }^{\mathrm{TM}}$. Uma vantagem deste procedimento é que o ambiente de simulação pode ser construído de forma modular, acelerando a obtenção de resultados. Por exemplo, os dados das features geradas podem ser visualizados na planilha Excel sem a necessidade de se verificar o valor de uma determinada variável ao longo da execução da simulação. Outra vantagem é a utilização da biblioteca de funções disponível no Excel, como por exemplo as funções para geração de números aleatórios utilizados para geração das features e da quantidade do lote. Desta forma, o usuário pode alterar o nível dos fatores diretamente na planilha, e com isso criar diferentes ordens de produção, cabendo ao usuário definir os dados das features, ferramentas e máquinas antes de realizar a geração de uma ordem. Para gerar uma ordem de produção é necessário que o usuário efetue os cinco passos descritos a seguir.

$1^{\circ}$ Passo - Cadastro das features: inicialmente, o usuário deve cadastrar as features, relacionando cada feature com um código específico que é utilizado pelo programa, como mostra a Figura 4.

Figura 4 - Planilha de edição de features

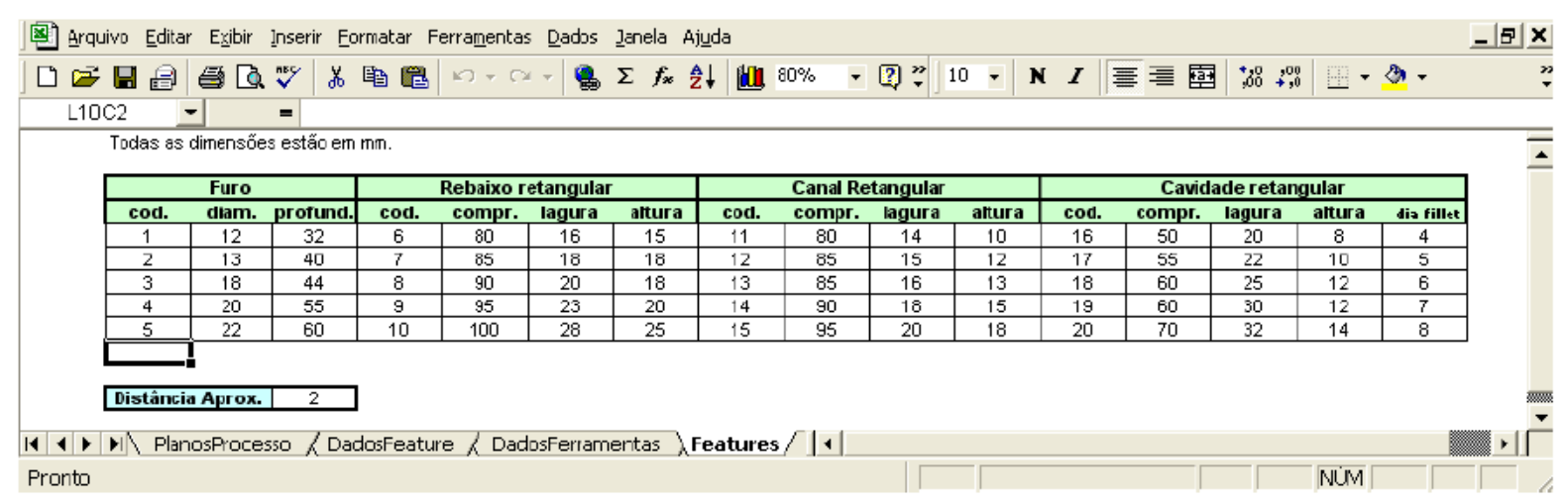

$2^{\circ}$ Passo - Cadastro das ferramentas: é preciso que o usuário cadastre as ferramentas que serão utilizadas na usinagem de cada feature, informando suas características, como o diâmetro $(\mathrm{mm})$ e/ou número de dentes, e suas respectivas 
condições de corte, tais como: profundidade de corte $(\mathrm{mm})$, avanço ( $\mathrm{mm} /$ rotação) e velocidade de corte (m/minuto), como mostrado na Figura 5.

Figura 5 - Planilha de cadastro de ferramentas

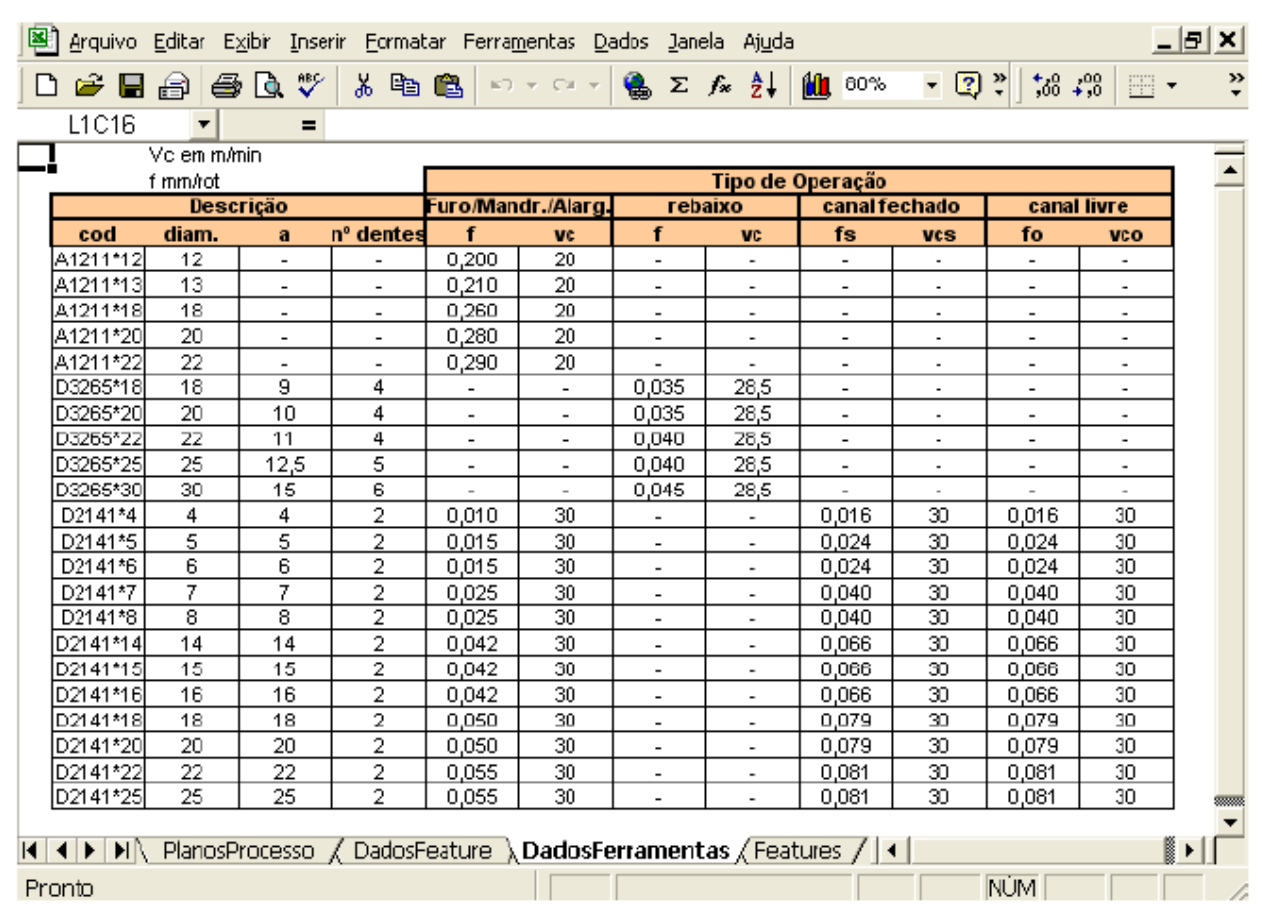

$3^{\circ}$ Passo - Cadastro das máquinas: em seguida é preciso que o usuário cadastre as máquinas que irão usinar as features cadastradas, além de relacionar cada ferramenta a uma dessas features, tal como mostra a Figura 6.

Figura 6 - Planilha de cadastro de máquinas

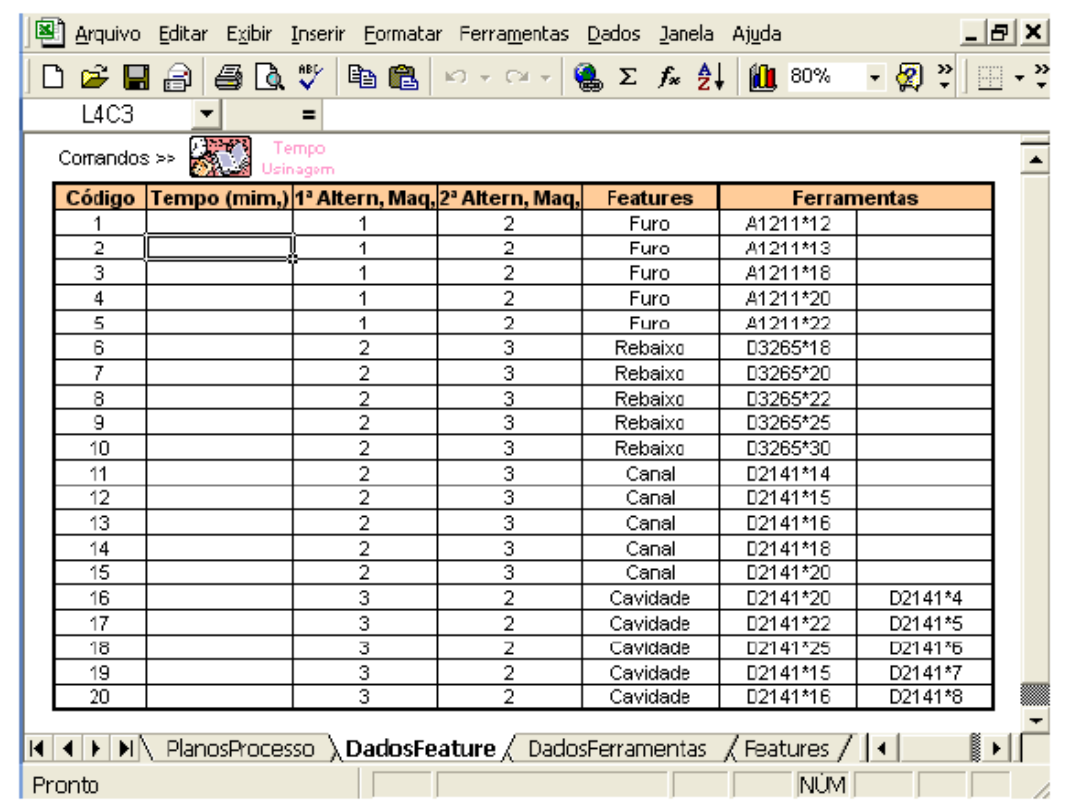

Revista Produção Online, Florianópolis, SC, v.14, n. 2, p. 648-678, abr./jun. 2014. 
$4^{\circ}$ Passo - Cálculo do tempo de usinagem: este passo permite ao usuário obter os tempos de usinagem para cada feature acionando-se o botão "Tempo Usinagem", em destaque na parte superior da planilha mostrada na Figura 7. Esses tempos de usinagem são calculados com base nos dados fornecidos para cada ferramenta cadastrada, admitindo a hipótese de que as máquinas selecionadas dispõem de potência suficiente para executar as operações de usinagem definidas para as ferramentas. O cálculo do tempo é realizado de acordo com as expressões apresentadas no trabalho de Ferreira e Wysk (2001a).

Figura 7 - Planilha de seleção de máquinas com o cálculo do tempo de usinagem

\begin{tabular}{|c|c|c|c|c|c|c|c|c|c|c|}
\hline 國 & Arqui & & Editar Exibir : & Inserir Formata & Ferramentas & Dados Janela & Ajüda & & - $a$ & $\underline{x}$ \\
\hline$\square$ & 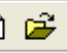 & & 1 間昌 员 & 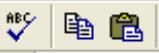 & $m+5 x+1$ & $8 \Sigma f_{x} \quad$ z $\downarrow$ & $80 \%$ & - ? ? & $=$ & 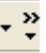 \\
\hline & $\mathrm{L} 4 \mathrm{O}$ & & + & $=0,408406$ & 70466423 & & & & & \\
\hline & Conan & dos & $\Rightarrow$ Ang & mpo & & & & & & $\Delta$ \\
\hline & Códig & & Tempo (mim,) & $1^{3}$ Altern, Maq & $2^{3}$ Altern, Maq & Features & Ferrar & nentas & & \\
\hline & 1 & & 0,3 & 1 & 2 & Furo & A1211*12 & & & \\
\hline & 2 & & 0.4 & 1 & 2 & Furo & A1211*13 & & & \\
\hline & 3 & & 0,5 & 1 & 2 & Furo & A1211*18 & & & \\
\hline & 4 & & 0,6 & 1 & 2 & Furo & $\mathrm{A} 1211 * 20$ & & & \\
\hline & 5 & & 0,7 & 1 & 2 & Furo & A1211*22 & & & \\
\hline & 6 & & 2,6 & 2 & 3 & Rebaixo & D3265*18 & & & \\
\hline & 7 & & 3,1 & 2 & 3 & Rebaixo & D3265*20 & & & \\
\hline & 8 & & 3,2 & 2 & 3 & Rebaixo & D3265*22 & & & \\
\hline & 9 & & 3,1 & 2 & 3 & Rebaixo & $\mathrm{D} 3265 * 25$ & & & \\
\hline & 10 & & 2,9 & 2 & 3 & Rebaixo & D3265*30 & & & \\
\hline & 11 & & 1,0 & 2 & 3 & Canal & D2141*14 & & & \\
\hline & 12 & & 1,1 & 2 & 3 & Canal & D2141*15 & & & \\
\hline & 13 & & 1,2 & 2 & 3 & Canal & $\mathrm{D} 2141 * 16$ & & & \\
\hline & 14 & & 1,2 & 2 & 3 & Canal & D2141*18 & & & \\
\hline & 15 & & 1,4 & 2 & 3 & Canal & $\mathrm{D} 2141 * 20$ & & & \\
\hline & 16 & & 2,3 & 3 & 2 & Cavidade & $D 2141 * 20$ & $D 2141 * 4$ & & \\
\hline & 17 & & 2,2 & 3 & 2 & Cavidade & $D 2141 * 22$ & $D 2141 * 5$ & & \\
\hline & 18 & & 2,9 & 3 & 2 & Cavidade & $D 2141^{*} 25$ & D2141*6 & & \\
\hline & 19 & & 2.8 & 3 & 2 & Cavidade & D2141*15 & $D 2141 * 7$ & & \\
\hline & 20 & & 3.4 & 3 & 2 & Cavidade & $\mathrm{D} 2141 * 16$ & $\mathrm{D} 2141^{\star} 8$ & & \\
\hline |4 & 11 & & PlanosProcess & $50>$ DadosF & ture & osFerramentas & 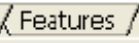 & $\mid 4$ & $\bullet$ & \\
\hline Pro & onto & & & & & & NÜM & & & \\
\hline
\end{tabular}

$5^{\circ}$ Passo - Geração da ordem de produção: de posse dos dados obtidos nos passos anteriores, pode-se gerar as ordens de produção de acordo com o nível definido para os fatores relacionados à peça, tais como: features por peça, features duplicadas e quantidade do lote. Assim, inicialmente a planilha "PlanoProcesso" está vazia, pois o nível desses fatores ainda não foi definido. Isso é realizado por meio da janela "Dados do Experimento", exibida quando o ícone "Gerar Peça" é acionado, como mostrado na Figura 8. Deve-se mencionar que os quatro passos anteriores foram realizados uma única vez, enquanto este quinto passo era realizado sempre que se desejava alterar o nível de um dos fatores relacionados à peça. 
Figura 8 - Janela para aquisição dos dados do experimento

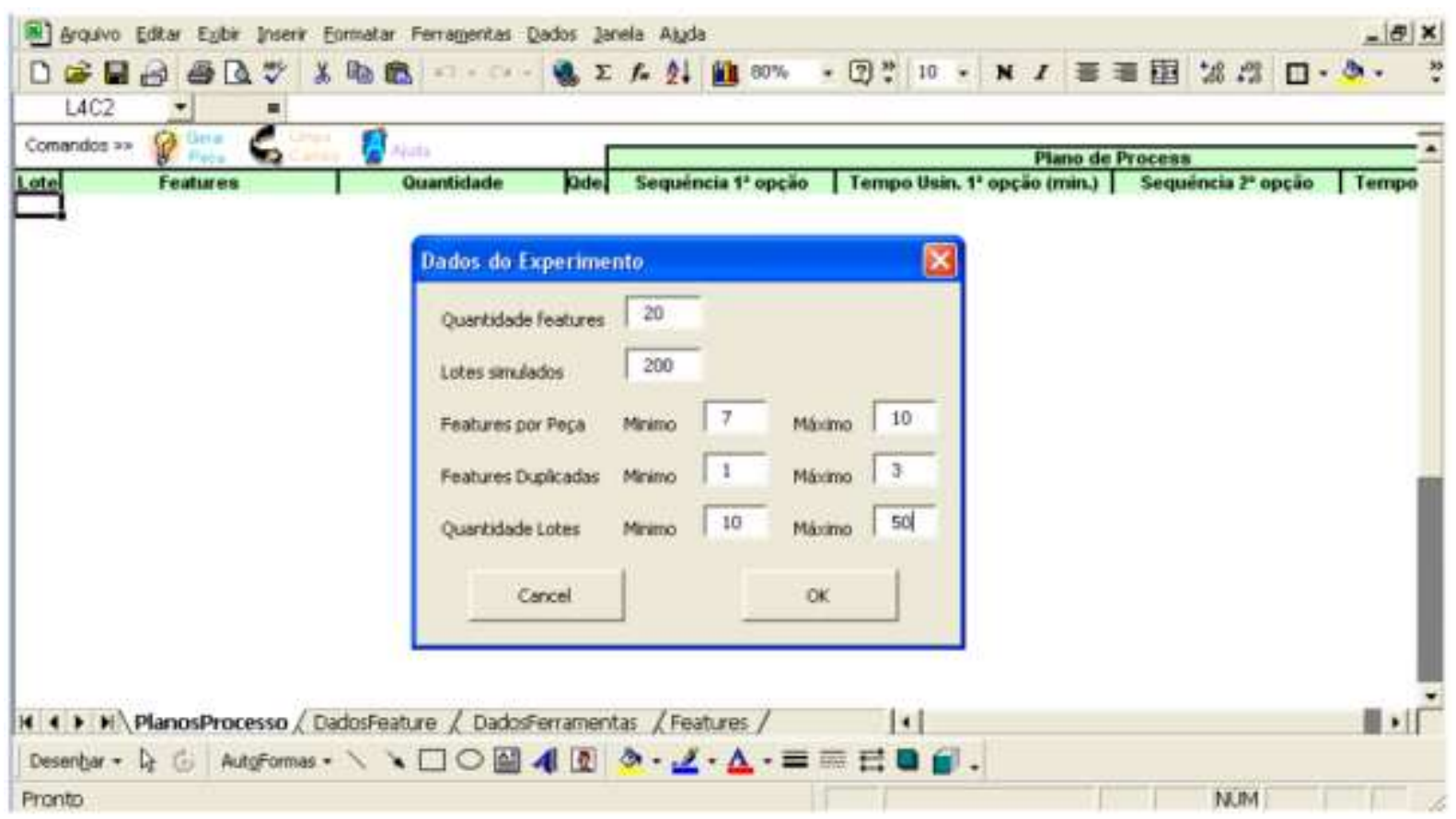

Nessa janela, o campo "Quantidade Features" permite ao usuário selecionar a quantidade de features para a geração das pecas. Neste trabalho foram cadastradas vinte features diferentes ( $1^{\circ}$ Passo), divididas em quatro tipos. Assim, nesse campo define-se uma quantidade de features menor ou igual à quantidade de features disponíveis, para ser utilizada na geração das peças.

Já o campo "Quantidade de Lotes" define a quantidade de ordens de produção que são geradas pelo sistema. Assim, se o usuário deseja simular a fabricação de 500 lotes, ele deverá informar este valor no campo "Quantidade de Lotes". Neste trabalho foram geradas 200 ordens, o que corresponde à maior quantidade de ordens consideradas para o nível alto do fator lotes simulados.

Os três campos seguintes correspondem ao nível para os fatores features por peça, features duplicadas e quantidade do lote, respectivamente. Cada fator dispõe de dois campos, nos quais insere-se a faixa de variação de cada nível (baixo e alto). Por exemplo, supondo que se deseja gerar ordens cujo fator quantidade do lote esteja no nível baixo, a quantidade mínima será 10 lotes e a quantidade máxima 50 lotes, valores que deverão ser introduzidos nos campos "Mínimo" e "Máximo", respectivamente, do campo "Quantidade lote". O mesmo procedimento deverá ser realizado para os outros dois fatores. 
Após inserir os valores desejados em todos os campos da janela "Dados do Experimento", o usuário aciona o botão "OK", iniciando-se o processo de geração das ordens. Os valores inseridos nos campos da janela "Dados do Experimento" são lidos pelo programa, e a ordem de fabricação é gerada, tal como mostra a Figura 9.

Figura 9 - Planilha com a ordem de produção gerada

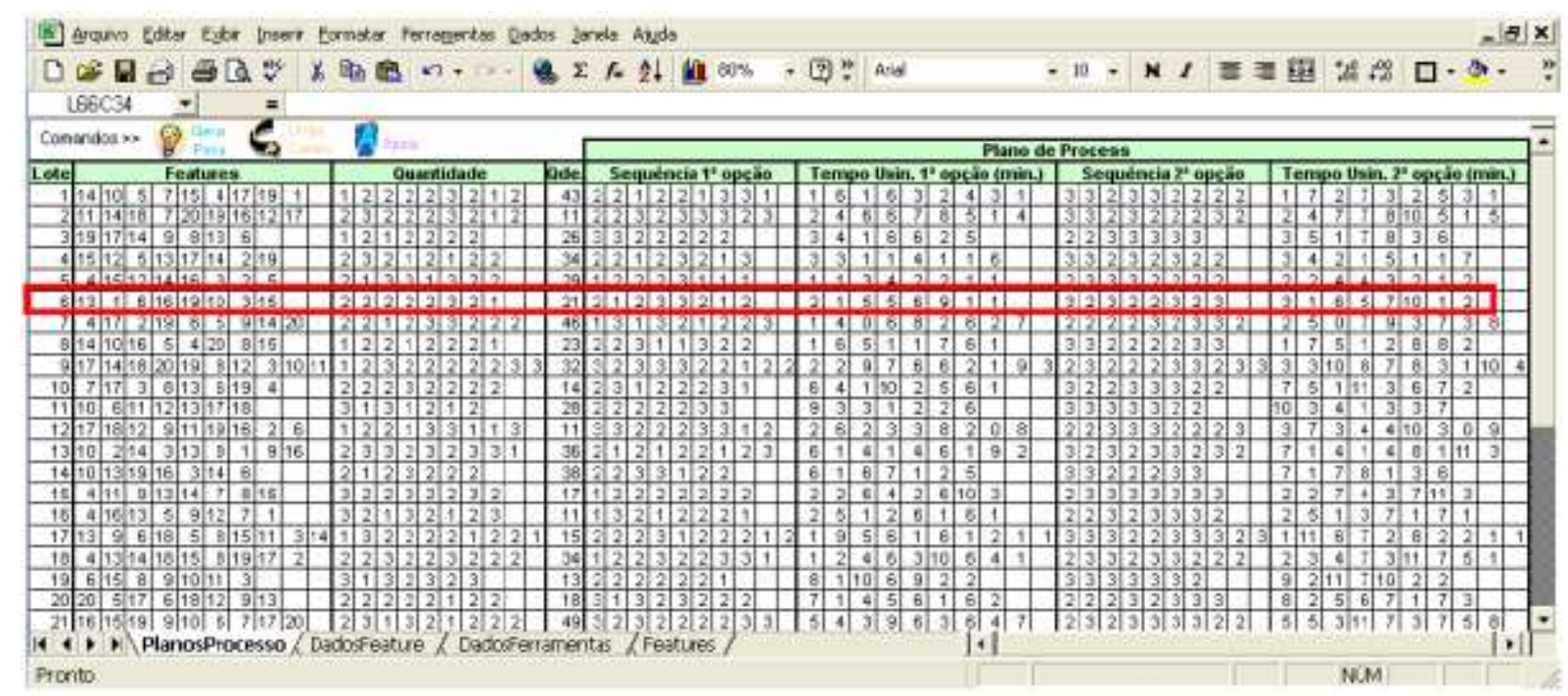

\subsection{Sistema de Manufatura}

\subsubsection{Descrição do Sistema de Manufatura}

O sistema de manufatura é composto por cinco máquinas, sendo duas fresadoras convencionais, dois centros de usinagem CNC e uma furadeira convencional (Figura 10). Assim, cada fresadora é atendida por um operador, enquanto apenas um operador é disponibilizado tanto para controlar os centros de usinagem CNC como a furadeira. $60 \%$ do tempo do operador que atende os centros de usinagem CNC e a furadeira são dedicados à furadeira, enquanto $20 \%$ são disponibilizados para cada centro de usinagem CNC. 
Figura 10 - Sistema de manufatura modelado neste trabalho

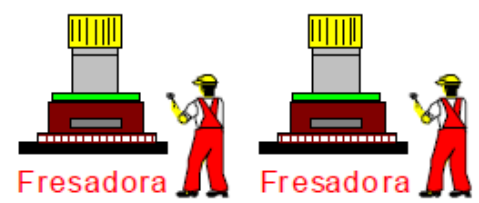

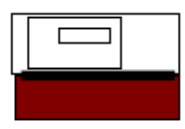

Centro Usinagem CNC

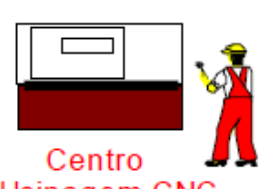

Usinagem CNC

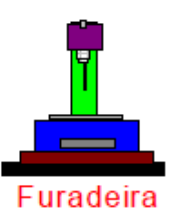

\subsubsection{Features Usinadas em Cada Estação}

O tipo de feature que compõe a peça é escolhido aleatoriamente, por isso a probabilidade de uma peça ser composta por um determinado tipo de feature é aproximadamente a mesma. Por outro lado, as máquinas com capacidade de produzir cada tipo de feature foram definidas previamente, conforme mostra a Tabela 4.

\subsubsection{Procedimento para a seleção de estações}

A estratégia adotada para a seleção de um recurso alternativo, no caso de um plano de processo com alternativas, baseou-se no estoque em processo. Assim, dentre dois recursos diferentes selecionados para fabricação de um lote de peças, aquele que tivesse a menor quantidade de lotes aguardando para serem fabricados é preferencialmente selecionado. Porém, na hipótese de inexistência de estoque em processo, ou estoques iguais, o recurso previamente selecionado como primeira alternativa é utilizado.

Tabela 4 - Features usinadas em cada tipo de máquina no sistema

\begin{tabular}{ccc}
\hline Máquinas & $\begin{array}{c}\text { Plano processo } \\
\text { sem alternativas }\end{array}$ & $\begin{array}{c}\text { Plano processo } \\
\text { com alternativas }\end{array}$ \\
\hline Furadeira & Furo & Furo \\
Fresadora Vertical & Rebaixo, Canal & Furo, Rebaixo, Canal, Cavidade \\
Fresadora Vertical & Rebaixo, Canal & Furo, Rebaixo, Canal, Cavidade \\
Centro de usinagem & Cavidade & Furo, Rebaixo, Canal, Cavidade \\
Centro de usinagem & Cavidade & Furo, Rebaixo, Canal, Cavidade \\
\hline
\end{tabular}




\subsubsection{Variáveis do sistema de manufatura}

Algumas variáveis da simulação, bem como algumas distribuições de probabilidade tiveram seus valores adotados como descritos a seguir:

- tempo de chegada: distribuição uniforme cujo valor faria de acordo com o tempo de usinagem do lote anterior e o nível adotado para esse fator, sendo que o tempo para a chegada da primeira ordem é igual a zero;

- tempo de transporte: distribuição uniforme com valor mínimo de 3 minutos e máximo de 10 minutos;

- tempo de set-up: na furadeira foi admitido igual a 10 minutos enquanto para a fresadora e centro de usinagem CNC foi considerado igual a 20 minutos;

- tempo de usinagem: esse tempo é definido no plano de processos, e caso haja alternativas no plano de processo, o tempo é determinado considerando uma penalidade ( $20 \%$ ou $40 \%)$, decorrente à seleção de alternativas.

\subsection{Penalidades sobre o tempo de usinagem}

Neste estudo avaliou-se o efeito de duas penalidades (20\% e 40\%) atuando sobre o tempo de usinagem, quando uma alternativa do plano de processos é utilizada na usinagem de um lote. Por exemplo, se o tempo de usinagem para um determinado lote for de 90 minutos na máquina inicialmente selecionada, mas caso essa máquina não esteja disponível o tempo de usinagem em uma máquina alternativa aumentará para 108 minutos, se a penalidade considerada for de $20 \%$, ou 126 minutos, se a penalidade considerada for de $40 \%$.

A escolha da penalidade se baseia na hipótese de que não existem duas máquinas disponíveis de mesma eficiência para executar uma mesma tarefa. Embora isso possa ocorrer, é preferível analisar a pior condição, pois as máquinas de maior eficiência normalmente estão menos disponíveis por serem preferidas para a fabricação das peças. 


\subsection{Etapas da Simulação}

Inicialmente o usuário define os dados da simulação, tais como a quantidade de lotes simulados, o tipo de plano e a localização dos arquivos de dados e resultados. Em seguida são inseridas algumas condições iniciais da simulação, como a inicialização das variáveis de estado (número de lotes no sistema, estoque em processo, produtividade, utilização dos recursos, tempo de chegada do próximo lote, etc.) e algumas constantes (tempo de set-up, tempo de transporte, etc.).

A chegada de um lote é o evento que inicia o processo de simulação, já que o tempo para a chegada do primeiro lote é igual a zero. Portanto, tendo em vista que os lotes de peças a serem utilizados na simulação já foram definidos na etapa anterior, é necessário que o modelo de simulação reproduza as características desejadas do comportamento do sistema de acordo com o lote a ser produzido, para o qual foi definida uma combinação de níveis dos fatores que se desejava avaliar. Assim, o modelo deve diferenciar cada lote quanto ao tipo de features das peças, o número de features por peça, o número de features duplicadas e a quantidade do lote. Isso foi realizado a partir do arquivo de ordens gerado no Excel.

Em seguida, de acordo com as features existentes em cada lote, são definidas as operações a serem executadas, a partir das quais pode-se definir as máquinas para fabricar o lote. Entretanto, antes disso era necessário verificar o tipo de plano escolhido pelo usuário: no caso de um plano sem alternativas, a máquina era definida como primeira opção para a usinagem da feature. No caso da presença de alternativas, o estoque em processo era levado em conta para seleção da máquina. Assim, se a primeira opção de máquina para a usinagem da feature possui estoque em processo menor ou igual ao da segunda opção, a primeira opção é selecionada, caso contrário a segunda opção é preferida para a usinagem da feature.

A próxima etapa consiste em determinar o tempo de usinagem, a qual é realizada considerando-se o tipo de plano, já que no plano de processo com alternativas existe uma penalidade associada à escolha da segunda opção de máquina, como já foi apontado anteriormente. 
Embora a princípio todos os recursos foram considerados disponíveis, antes de se realizar a operação selecionada é verificada a existência de estoques em processo nos recursos. Caso não haja estoque em processo, a operação é realizada imediatamente. Do contrário, é contabilizado o tempo que o lote permanece estocado até o início da sua usinagem. Antes de se iniciar a usinagem do lote, é definido o tempo de set-up de acordo com a máquina utilizada.

O lote só deixa a máquina selecionada caso não haja mais nenhuma operação a ser realizada na máquina atual. No caso do plano de processo com alternativas, antes do lote deixar a máquina, verificada-se a possibilidade da segunda opção de máquina para a próxima operação ser igual à máquina atual. Isso é realizado comparando-se o estoque em processo no recurso selecionado para a próxima operação (primeira opção de máquina) com o recurso em questão (segunda opção de máquina). Caso a segunda opção de máquina selecionada para a próxima operação seja igual à máquina atual, avalia-se o estoque em processo no recurso definido como segunda opção de máquina. Caso o estoque em processo no recurso selecionado como primeira opção de máquina para a execução da próxima operação seja igual a zero, o lote é deslocado para esse recurso. Caso contrário (isto é, inexistência de estoque em processo), a operação seria realizada na máquina atual, e desse modo seria obtido um ganho com a redução do número de set-ups, pois o set-up não será realizado novamente.

Ao final de todas as operações é verificado se ainda há mais alguma operação a ser realizada. Caso houver tal operação, uma nova operação é selecionada de acordo com a sequência definida na planilha de geração da ordem. Caso não houver mais operações a serem executadas, o lote deixa o sistema, e suas estatísticas são coletadas, tais como: ao tempo de espera, tempo de entrada no sistema, tempo de saída. As variáveis de desempenho são calculadas baseandose nessas estatísticas.

\section{RESULTADOS}

\subsection{Resultados da simulação}


Os resultados obtidos após a execução da simulação relacionam os níveis de cada fator e suas respectivas variáveis de resposta, tal como mostra a Figura 11.

Figura 11 - Planilha contendo alguns resultados da simulação

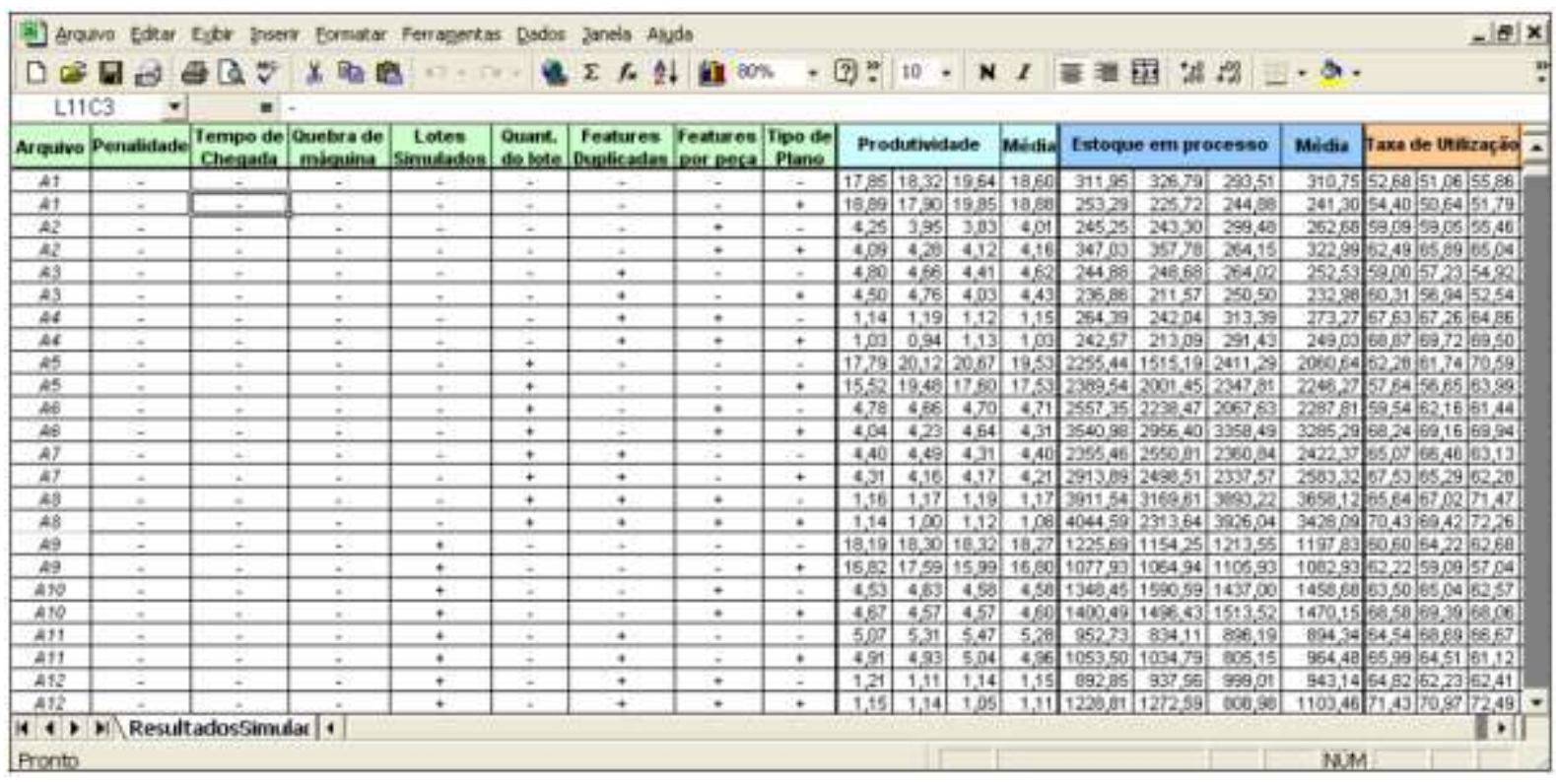

Para analisar esses resultados foi efetuada a análise de variância (ANOVA) nas Tabelas 5, 6, 7 (penalidade de 20\%) e Tabelas 8, 9, 10 (penalidade de 40\%).

\subsection{Análise dos resultados}

As análises dos resultados foram feitas para cada variável de resposta considerando a análise das tabelas de ANOVA. Em relação à ANOVA, as análises foram realizadas comparando os efeitos de cada fator a partir dos valores da soma dos quadrados (SS). 
Tabela 5 - ANOVA na produtividade considerando uma penalidade de $20 \%$

\begin{tabular}{|c|c|c|c|c|c|}
\hline Fonte de Variação & SS & DF & MS & $\mathbf{F}_{\mathbf{0}}$ & $\mathbf{P}$ \\
\hline Tempo de chegada & 693 & 1 & 693 & 8109,74 & 0,000 \\
\hline Quebra de máquina & 6,46 & 1 & 6,46 & 75,58 & 0,000 \\
\hline Lotes simulados & 3,69 & 1 & 3,69 & 43,13 & 0,000 \\
\hline Quantidade do lote & 8,41 & 1 & 8,41 & 98,46 & 0,000 \\
\hline Features duplicadas & 6157,93 & 1 & 6157,93 & 72062,5 & 0,000 \\
\hline Features por peça & 6641,02 & 1 & 6641,02 & 77715,88 & 0,000 \\
\hline Tipo de plano & 79,33 & 1 & 79,33 & 928,4 & 0,000 \\
\hline Interações entre 2 fatores & 3048,9 & 21 & 145,19 & 1699,03 & 0,000 \\
\hline Interações entre 3 fatores & 244,2 & 35 & 6,98 & 81,64 & 0,000 \\
\hline Interações entre 4 fatores & 56,2 & 35 & 1,6 & 18,77 & 0,000 \\
\hline Interações entre 5 fatores & 12,7 & 21 & 0,61 & 7,1 & 0,000 \\
\hline Interações entre 6 fatores & 3,2 & 7 & 0,46 & 5,4 & 0,000 \\
\hline Interações entre 7 fatores & 0,3 & 1 & 0,29 & 3,45 & 0,064 \\
\hline Erro & 21,9 & 256 & 0,09 & & \\
\hline Total & 16977,2 & 383 & & & \\
\hline
\end{tabular}

Tabela 6 - ANOVA para o estoque em processo considerando uma penalidade de $20 \%$

\begin{tabular}{llllll}
\hline \multicolumn{1}{c}{ Fonte de Variação } & \multicolumn{1}{c}{ SS } & DF & \multicolumn{1}{c}{ MS } & \multicolumn{1}{c}{$\mathbf{F}_{\mathbf{0}}$} & P \\
\hline Tempo de chegada & 630592293,00 & 1 & 630592293,00 & 11786,12 & 0,000 \\
Quebra de máquina & 292257,00 & 1 & 292257,00 & 5,46 & 0,020 \\
Lotes simulados & 205263417,00 & 1 & 205263417,00 & 3836,49 & 0,000 \\
Quantidade do lote & 470611804,00 & 1 & 470611804,00 & 8795,99 & 0,000 \\
Features duplicadas & 6809986,00 & 1 & 6809986,00 & 127,28 & 0,000 \\
Features por peça & 58047739,00 & 1 & 58047739,00 & 1084,94 & 0,000 \\
Tipo de plano & 65309982,00 & 1 & 65309982,00 & 1220,68 & 0,000 \\
Interações entre 2 fatores & 984010516 & 21 & 205275354 & 875,8 & 0,000 \\
Interações entre 3 fatores & 331174348 & 35 & 46857644 & 176,85 & 0,000 \\
Interações entre 4 fatores & 68516728 & 35 & 9462124 & 36,59 & 0,000 \\
Interações entre 5 fatores & 10475114 & 21 & 1957621 & 9,32 & 0,000 \\
Interações entre 6 fatores & 354597 & 7 & 498815 & 0,95 & 0,471 \\
Interações entre 7 fatores & 53892 & 1 & 50657 & 1,01 & 0,317 \\
Erro & 13696761 & 256 & 53892 & & \\
Total & 2845209433 & 383 & & & \\
\hline
\end{tabular}

Tabela 7 - ANOVA para a utilização dos recursos considerando uma penalidade de $20 \%$

\begin{tabular}{llllll}
\hline \multicolumn{1}{c}{ Fonte de Variação } & \multicolumn{1}{c}{ SS } & DF & MS & F $_{\mathbf{0}}$ & P \\
\hline Tempo de chegada & 49535,05 & 1 & 49535,05 & 37310,36 & 0,000 \\
Quebra de máquina & 44,13 & 1 & 44,13 & 33,24 & 0,000 \\
Lotes simulados & 1140,57 & 1 & 1140,57 & 859,09 & 0,000 \\
Quantidade do lote & 333,13 & 1 & 333,13 & 250,91 & 0,000 \\
Features duplicadas & 225,4 & 1 & 225,4 & 169,77 & 0,000 \\
Features por peça & 166,82 & 1 & 166,82 & 125,65 & 0,000 \\
Tipo de plano & 9718,77 & 1 & 9718,77 & 7320,28 & 0,000 \\
Interações entre 2 fatores & 10781,4 & 21 & 513,4 & 386,7 & 0,000 \\
Interações entre 3 fatores & 916,2 & 35 & 26,18 & 19,72 & 0,000 \\
Interações entre 4 fatores & 431,5 & 35 & 12,33 & 9,29 & 0,000 \\
Interações entre 5 fatores & 142,7 & 21 & 6,79 & 5,12 & 0,000 \\
Interações entre 6 fatores & 13 & 7 & 1,85 & 1,4 & 0,207 \\
Interações entre 7 fatores & 1 & 1 & 0,96 & 0,72 & 0,395 \\
Erro & 339,9 & 256 & 1,33 & & \\
Total & 73789,4 & 383 & & & \\
\hline
\end{tabular}


Tabela 8 - ANOVA para a produtividade considerando uma penalidade de $40 \%$

\begin{tabular}{llllll}
\hline \multicolumn{1}{c}{ Fonte de Variação } & \multicolumn{1}{c}{ SS } & \multicolumn{1}{c}{ DF } & \multicolumn{1}{c}{ MS } & \multicolumn{1}{c}{$\mathbf{F}_{\mathbf{0}}$} & \multicolumn{1}{c}{ P } \\
\hline Tempo de chegada & 587,66 & 1 & 587,66 & 6171,76 & 0,000 \\
Quebra de máquina & 4,05 & 1 & 4,05 & 42,5 & 0,000 \\
Lotes simulados & 3,58 & 1 & 3,58 & 37,6 & 0,000 \\
Quantidade do lote & 6,58 & 1 & 6,58 & 69,14 & 0,000 \\
Features duplicadas & 5969,58 & 1 & 5969,58 & 62693,62 & 0,000 \\
Features por peça & 6424,24 & 1 & 6424,24 & 67468,64 & 0,000 \\
Tipo de plano & 43,67 & 1 & 43,67 & 458,66 & 0,000 \\
Interações entre 2 fatores & 2835,7 & 21 & 135,03 & 1418,16 & 0,000 \\
Interações entre 3 fatores & 202,3 & 35 & 5,78 & 60,7 & 0,000 \\
Interações entre 4 fatores & 49,6 & 35 & 1,42 & 14,88 & 0,000 \\
Interações entre 5 fatores & 11,2 & 21 & 0,53 & 5,61 & 0,000 \\
Interações entre 6 fatores & 2,7 & 7 & 0,39 & 4,09 & 0,000 \\
Interações entre 7 fatores & 0,03 & 1 & 0,03 & 0,36 & 0,548 \\
Erro & 24,4 & 256 & 0,1 & & \\
Total & 16165,3 & 383 & & & \\
\hline
\end{tabular}

Tabela 9 - ANOVA para o estoque em processo considerando uma penalidade de $40 \%$

\begin{tabular}{llllll}
\hline \multicolumn{1}{c}{ Fonte de Variação } & \multicolumn{1}{c}{ SS } & \multicolumn{1}{c}{ DF } & \multicolumn{1}{c}{ MS } & \multicolumn{1}{c}{$\mathbf{F}_{\mathbf{0}}$} & P \\
\hline Tempo de chegada & 835349880 & 1 & 835349880 & 9942,08 & 0,000 \\
Quebra de máquina & 210259 & 1 & 210259 & 2,50 & 0,115 \\
Lotes simulados & 297277858 & 1 & 297277858 & 3538,11 & 0,000 \\
Quantidade do lote & 637486020 & 1 & 637486020 & 7587,16 & 0,000 \\
Features duplicadas & 1701009 & 1 & 1701009 & 20,24 & 0,000 \\
Features por peça & 88374661 & 1 & 88374661 & 1051,81 & 0,000 \\
Tipo de plano & 41458075 & 1 & 41458075 & 493,42 & 0,000 \\
Interações entre 2 fatores & 1300582867,00 & 21 & 61932517,00 & 737,10 & 0,000 \\
Interações entre 3 fatores & 421108103,00 & 35 & 12031660,00 & 143,20 & 0,000 \\
Interações entre 4 fatores & 84759452,00 & 35 & 2421699,00 & 28,82 & 0,000 \\
Interações entre 5 fatores & 14259072,00 & 21 & 679003,00 & 8,08 & 0,000 \\
Interações entre 6 fatores & 380197,00 & 7 & 54314,00 & 0,65 & 0,717 \\
Interações entre 7 fatores & 38404,00 & 1 & 38404,00 & 0,46 & 0,500 \\
Erro & 21509549,00 & 256 & 84022,00 & & \\
Total & 3744495406,00 & 383 & & & \\
\hline
\end{tabular}

Tabela 10 - ANOVA para a utilização dos recursos considerando uma penalidade de $40 \%$

\begin{tabular}{llllll}
\hline \multicolumn{1}{c}{ Fonte de Variação } & \multicolumn{1}{c}{ SS } & \multicolumn{1}{c}{ DF } & \multicolumn{1}{c}{ MS } & \multicolumn{1}{c}{$\mathbf{F}_{\mathbf{0}}$} & \multicolumn{1}{c}{ P } \\
\hline Tempo de chegada & 45877,65 & 1 & 45877,65 & 35245,83 & 0,000 \\
Quebra de máquina & 56,92 & 1 & 56,92 & 43,73 & 0,000 \\
Lotes simulados & 1284,03 & 1 & 1284,03 & 986,47 & 0,000 \\
Quantidade do lote & 244,68 & 1 & 244,68 & 187,98 & 0,000 \\
Features duplicadas & 207,88 & 1 & 207,88 & 159,7 & 0,000 \\
Features por peça & 166,14 & 1 & 166,14 & 127,64 & 0,000 \\
Tipo de plano & 11122,69 & 1 & 11122,69 & 8545,09 & 0,000 \\
Interações entre 2 fatores & 9490,70 & 21 & 451,94 & 347,20 & 0,000 \\
Interações entre 3 fatores & 961,80 & 35 & 27,48 & 21,11 & 0,000 \\
Interações entre 4 fatores & 441,60 & 35 & 12,62 & 9,69 & 0,000 \\
Interações entre 5 fatores & 90,90 & 21 & 4,33 & 3,33 & 0,000 \\
Interações entre 6 fatores & 16,40 & 7 & 2,34 & 1,80 & 0,088 \\
Interações entre 7 fatores & 1,00 & 1 & 1 & 0,76 & 0,385 \\
Erro & 333,20 & 256 & 1,30 & & \\
Total & 70295,60 & 383 & & & \\
\hline
\end{tabular}




\subsubsection{Efeito dos fatores em relação à produtividade}

A partir das Tabelas do ANOVA 5 e 8, verifica-se que os fatores que mais influenciam a produtividade são features por peça, features duplicadas, tempo de chegada e tipo de plano, respectivamente. $O$ aumento no nível dos fatores features por peça e features duplicadas reduz a produtividade em razão de estarem relacionados ao aumento da complexidade das peças. Já o aumento do nível do fator tempo de chegada reduz a produtividade. Com relação ao fator tipo de plano, o uso de alternativas no plano de processo aumenta a produtividade, mostrando que o uso de um recurso alternativo, mesmo com menor eficiência, é benéfico à produtividade quando comparado à situação onde tal recurso não foi previsto, mesmo para uma penalidade de $40 \%$.

Ao observar-se a interação entre dois fatores, são identificadas interações onde os fatores envolvidos são aqueles de maior efeito sobre a produtividade. Além disso, verificou-se uma interação adicional entre o fator tempo de chegada e tipo de plano, a qual indica que os ganhos em produtividade com o uso de alternativas são maiores quando aumenta a ociosidade dos recursos no sistema.

\subsubsection{Efeito dos fatores em relação ao estoque em processo}

De acordo com as tabelas do ANOVA 6 e 9, verificou-se que a influência mais expressiva é causada pelos seguintes fatores: tempo de chegada, quantidade do lote, lotes simulados, features por peça e tipo de plano, respectivamente. $\mathrm{O}$ aumento do nível do fator tempo de chegada reduz o estoque em processo, pois aumenta o intervalo de tempo entre a chegada de uma ordem de fabricação e outra. Quanto maior o nível do fator quantidade do lote, maior a quantidade de peças existente nos lotes, e, conseqüentemente, maior o estoque em processo. Já o aumento nos lotes simulados aumenta o estoque em processo, pois reduz a possibilidade de uma máquina ficar ociosa durante um curto intervalo de tempo. Em relação ao fator features por peça, o aumento no nível do mesmo, que corresponde a uma maior complexidade da peça, resulta num maior estoque em processo. Por outro lado, no caso do fator features duplicadas, que também está relacionado a uma maior 
complexidade das peças, o aumento no nível desse fator causou uma ligeira redução no estoque em processo, em razão da redução de set-ups. No caso do fator tipo de plano, o efeito negativo mostra que o uso de alternativas possibilita uma redução do estoque em processo, mesmo que a penalidade seja de $40 \%$.

Verifica-se também que as interações observadas envolvem os fatores de maior efeito sobre o estoque em processo. Outra interação envolve os fatores quantidade de lotes e lotes simulados, mostrando que o efeito do fator quantidade do lote sobre o estoque em processo é maior quando o nível do fator lotes simulados é alto. Foram verificadas também interações envolvendo o fator tipo de plano e os seguintes fatores: tempo de chegada, quantidade do lote, lotes simulados e features por peça, respectivamente. O efeito dessas interações consiste em uma maior redução do estoque em processo quando são utilizadas alternativas. Isso mostra que a utilização de alternativas em planos de processo beneficia a redução do estoque em processo, sobretudo no caso de aumento da ociosidade dos recursos, aumento da quantidade de ordens no sistema e aumento da incerteza quanto à chegada de uma ordem.

\subsubsection{Efeito dos fatores em relação à taxa de utilização dos recursos}

Segundo as tabelas do ANOVA 7 e 10, os fatores em relação à taxa de utilização destacam principalmente o efeito do fator tempo de chegada e tipo de plano, embora outros efeitos também se verifiquem para os seguintes fatores: features por peça, lotes simulados e quantidade do lote, respectivamente. $O$ aumento no nível do fator tempo de chegada está relacionado à redução da utilização dos recursos, pois leva a uma maior ociosidade no sistema. Em relação ao fator tipo de plano, verifica-se que o mesmo influencia positivamente a taxa de utilização pois o uso de alternativas possibilita selecionar um recurso de menor taxa de ocupação para a fabricação de uma peça. Já o fator features por peça produz um efeito positivo sobre a taxa de utilização. A razão disso é que o aumento do nível do fator features por peça aumenta a complexidade das peças, o que irá demandar um tempo de fabricação maior. O aumento do fator lotes simulados aumenta a taxa de utilização porque reduz as chances do sistema ficar ocioso, pois diminui a incerteza 
quanto à chegada de uma ordem. O fator quantidade do lote possui um efeito positivo sobre a taxa de utilização, pois os recursos serão mantidos ocupados por mais tempo.

\section{CONCLUSÕES}

De um modo geral, a análise dos resultados evidenciou que os fatores tempo de chegada, features duplicadas e features por peça, lotes simulados, quantidade do lote e tipo de plano, são os que mais influenciam a produtividade, o estoque em processo e a taxa de utilização. No entanto, dentre esses fatores apenas a quantidade do lote e o tipo de plano podem, de fato, ser controlados na prática, pois os demais fatores estão ligados ao ambiente externo do sistema de manufatura. Assim, quanto maior o tamanho do lote menor a quantidade de set-ups a serem realizados, portanto maior a produtividade. Porém, quanto maior o tamanho do lote, maior o estoque em processo. Portanto, apenas a definição da quantidade do lote por si só não basta, por isso a utilização de planos de processo com alternativas pode ser considerada mais uma opção para gerir os recursos no chão de fábrica. Em relação à produtividade, considerando a variação dos demais fatores, obteve-se um ganho $12,7 \%$ em média com a utilização de alternativas. Quanto ao estoque em processo, a utilização de alternativas no plano de processo possibilitou uma redução do estoque em processo de 19,0\% em média. O uso de alternativas também aumentou a taxa de utilização dos recursos em $21,3 \%$ em média.

Quanto à estratégia para seleção da máquina alternativa, recomenda-se selecionar um recurso com base no estoque em processo. A vantagem em utilizar essa estratégia é que ela pode ser facilmente implementada no chão de fábrica, pois, em alguns casos, até mesmo visualmente pode-se identificar as máquinas com maior estoque, apesar de, eventualmente, outras estratégias poderem ser mais eficientes. Já em relação à quantidade de alternativas, recomenda-se a utilização de poucas alternativas, de preferência apenas duas, já que é melhor uma baixa quantidade de boas alternativas que uma grande quantidade de alternativas de baixa eficiência, como sugere Usher (2003). 
Em geral, os benefícios da utilização de alternativas podem variar de um sistema de manufatura para outro, por isso a penalidade máxima a ser adotada na seleção de uma alternativa também pode variar. Assim, com base nos resultados obtidos, recomenda-se utilizar uma alternativa cuja eficiência seja no máximo $40 \%$ inferior à eficiência do recurso originalmente selecionado, a menos que haja estudos comprovando que uma penalidade maior possa ser adotada. Uma das principais limitações deste estudo é a necessidade de testar as sugestões propostas em um sistema de manufatura real. Assim, estudos futuros podem ser realizados para atender essa necessidade, bem como avaliar as possibilidades de integrar o uso de máquinas alternativas junto aos métodos existentes de planejamento e controle da produção.

Como neste trabalho buscou-se avaliar do ponto de vista operacional se a presença de alternativas de máquinas era vantajosa (incluindo penalidades), recomenda-se em trabalhos futuros a execução de uma análise econômica, a qual não foi o foco deste trabalho.

\section{SOFTWARES UTILIZADOS}

Neste trabalho foram utilizados os seguintes softwares: (a) o Arena ${ }^{\mathrm{TM}}$ foi utilizado para a execução das simulações; (b) o Minitab ${ }^{\mathrm{TM}}$ para a aplicação do ANOVA; (c) o Microsoft Excel ${ }^{\mathrm{TM}}$ para a construção das peças baseadas nas features; (d) o Microsoft Visual Basic ${ }^{\mathrm{TM}}$ para o preparo dos dados advindos das planilhas em Excel para entrada no software Arena.

\section{REFERÊNCIAS}

AHKIOON S., BULGAK A.A. \& BEKTAS T. Cellular manufacturing systems design with routing flexibility, machine procurement, production planning and dynamic system reconfiguration. International Journal of Production Research, v.47, n.6, p.1573-1600, 2009. http://dx.doi.org/10.1080/00207540701581809

\section{BARRETO, G.J. ET AL. Revisão bibliográfica sobre a manufatura ágil e} comparação e diferenciação entre três eras produtivas, v. 5, v.1, 2005.

BAYKASOGLU A., ÖZBAKIR L. Analysing the effect of flexibility on manufacturing systems performance. Journal of Manufacturing Technology Management, v.19, n.2, p. 172-193, 2008. http://dx.doi.org/10.1108/17410380810847909 
BECKENDORFF, U., KREUTZFELDT, J. \& ULLMANN, W. Reactive workshop scheduling based on alternative routings. CONFERENCE ON FACTORY

AUTOMATION AND INFORMATION MANAGEMENT.Proceedings... Boca Raton: CRC Press, p. 875-885, 1991.

CAPRIHAN, R. \& WADHWA, S. Impact of Routing Flexibility on the Performance of an FMS - A Simulation Study. International Journal of Flexible Manufacturing Systems, v.9, p. 273-298, 1997. http://dx.doi.org/10.1023/A:1007917429815

CHAN, F.T.S. Effects of Dispatching and Routeings Decisions on the Performance of a Flexible Manufacture Systems. International Journal of Advanced Manufacture Technology, v.21, p. 328-338, 2003. http://dx.doi.org/10.1007/s001700300038

CHANG, H.C. \& CHEN, F. F. A Dynamic programming based process planning selection strategy considering utilization of machines, International Journal of Advanced Manufacture Technology, v.19, p. 97-105, 2002.

http://dx.doi.org/10.1007/s001700200002

CHANG, T.C.; WYSK, R.A. \& WANG, H.P. Computer-aided manufacturing. Prentice Hall International Series in Industrial and Systems Engineering, W.J. Fabrycky e J.H. Mize (eds.), 3rd Edition, 2006.

CHUNG, D.-H., \& Suh, S.-H. ISO 14649 - based nonlinear process planning implementation for complex machining. Computer-Aided Design, v.40, p.521-536, 2008. http://dx.doi.org/10.1016/j.cad.2008.01.009

DEJA M. \& SIEMIATKOWSKI M. S. Feature-based generation of machining process plans for optimised parts manufacture. Journal of Intelligent Manufacturing, p.116, 2012. http://dx.doi.org/10.1007/s10845-012-0633-x

FERREIRA, J.C.E. \& WYSK, R.A. An investigation of the influence of alternative process plans on equipment control. Journal of Manufacturing Systems, v.19, n.6, p. 393-406, 2001a. http://dx.doi.org/10.1016/S0278-6125(01)80011-X

FERREIRA, J.C.E. \& WYSK, R.A. On the efficiency of alternatives in process plans, Journal of de Brazilian Society Mechanical Sciences, v.23, n.3, p. 303-319, 2001b. http://dx.doi.org/10.1590/S0100-73862001000300003

JOSEPH O.A. \& SRIDHARAN R. Effects of flexibility and scheduling decisions on the performance of an FMS: simulation modelling and analysis. International Journal of Production Research, v. 50, n.7, p.2058-2078, 2012.

http://dx.doi.org/10.1080/00207543.2011.575091

Kis, T. Job shop scheduling with processing alternatives. European Journal of Operational Research, v.151, p.307-332, 2003.

http://dx.doi.org/10.1016/S0377-2217(02)00828-7 
LAW, A. M. \& KELTON, W.D. Simulation modeling and analysis. 3rd ed. McGrawHill, 2000.

LI, X., GAO, L., ZHANG, C. AND SHAO, X. A review on Integrated Process Planning and Scheduling. International Journal of Manufacturing Research, v.5, n.2, p.161-180, 2010. http://dx.doi.org/10.1504/IJMR.2010.031630

MAHMOODI, F.; MOSIER, C. T. \& MORGAN, J.R. The effects of scheduling rules and routing flexibility on the performance of a random flexible manufacturing system. International Journal of Flexible Manufacturing Systems, v.11, n.3, p. 271-289, 1999. http://dx.doi.org/10.1023/A:1008165212489

MAHESH O. \& SRINIVASAN G. Incremental cell formation considering alternative machines. International Journal of Production Research, v.40, n. 14, p.32913310, 2002. http://dx.doi.org/10.1080/00207540210146189

MONTGOMERY, D.C. Design and Analysis of experiments. 4th ed. John Wiley \& Sons, 1997.

Nonaka, Y. et al. Scheduling with alternative routings in CNC workshops. CIRP Annals - Manufacturing Technology, v. 61, p.449-454, 2012.

OLIVEIRA, M.J.; SABBADINI, F. \& CHAMOVITZ, I. Uma plataforma de simulação visual em 3d orientada para o ciclo de vida das entidades, v. 9, n. 2, 2009.

PEREIRA, F.P.; DAL FORNO, A.J. \& TUBINO, D.F. A flexibilidade no contexto do desenvolvimento de fábricas inteligentes. Revista Científica Eletrônica de Engenharia de Produção, v. 8, n. 2, 2008.

PHANDEN R. K., JAIN A. \& VERMA R. Integration of process planning and scheduling: a state-of-the-art review. International Journal of Computer Integrated Manufacturing, v.24, n.6, p.517-534, 2011.

http://dx.doi.org/10.1080/0951192X.2011.562543

Prabhu P. et al. An operations network generator for computer aided process planning. Journal of Manufacturing Systems, v.9, n.4, p.283-291, 1990. http://dx.doi.org/10.1016/0278-6125(90)90036-H

SAYGYN, C.; CHEN, F.F. \& SINGH, J. Real-time manipulation of alternative routeings in flexible manufacture systems: a simulation study. International Journal of Advanced Manufacture Technology, v.18, p.755-763, 2001.

http://dx.doi.org/10.1007/s001700170019

SHAH, J.J. \& MÄNTYLÄ, M. Parametric and feature-based cad/cam: concepts, techniques, and applications, John Wiley, New York, 1995. 
SOFIANOPOLOU, S. Manufacturing cells design with alternative process plans and/or replicate machines. International Journal of Production Research, v.37, p.707-720, 1999. http://dx.doi.org/10.1080/002075499191742

SORMAZ D. N. et al. Integration of product design, process planning, scheduling, and FMS control using XML data representation. Robotics and ComputerIntegrated Manufacturing, v. 26 p.583-595, 2010.

http://dx.doi.org/10.1016/j.rcim.2010.07.014

SORMAZ, D. N., \& KHOSHNEVIS, B. Generation of alternative process plans in integrated manufacturing systems. Journal of Intelligent Manufacturing, v.14, n.5, p.509-526, 2003. http://dx.doi.org/10.1023/A:1027302604072

USHER, J.M. Evaluating the impact of alternative plans on manufacturing performance. Computers \& Industrial Engineering, v.45, p. 585-596, 2003. http://dx.doi.org/10.1016/S0360-8352(03)00076-7

WANG, L. AND SHEN, W. Process planning and scheduling for distributed manufacturing. Springer-Verlag London Limited, London, UK, 2007. http://dx.doi.org/10.1007/978-1-84628-752-7

Weintraub, A. et al. Scheduling with alternatives: a link between process planning and scheduling. IEE Transactions, v.31, p.1093-1102, 1999.

http://dx.doi.org/10.1080/07408179908969910 http://dx.doi.org/10.1023/A:1007683710427

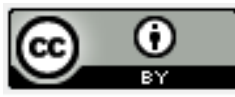

Artigo recebido em 10/10/2012 e aceito para publicação em 03/06/2013 DOI: $\underline{\text { http://dx.doi.org/10.14488/1676-1901.v14i2.1467 }}$ 